\title{
Impalement brain injury: report of five consecutive clinical cases
}

\author{
Aliyu Muhammad Koko ${ }^{*}$ (D) and Ali Lasseini
}

\begin{abstract}
Background: The management of impalement brain injury is very challenging, because of its complexity, risk of intracranial infection, neurological damage and functional impairment of the affected persons; in addition to the paucity of standardised treatments guidelines. The objective of this paper was to describe the clinical presentation and management outcome of patients admitted with impalement brain injuries in our centre.

Case presentation: Data of all patients with traumatic brain injury from January 2015 to November 2018 was collated from hospital medical record department and theatre operation register. Records of patients with impalement brain injury managed within the aforementioned period were extracted. We managed 5 cases (0.26\%) of impalement cranio-cerebral injuries out of the total 1913 cases of traumatic brain injury managed over the study period. All the patients were males with a mean age of 28 years. Alteration in the level of consciousness and bleeding scalp wound with impaled object were the main presenting symptoms. Three of the patients were presented in coma. The injury resulted from different causes and variable objects implicated. The impaled objects identified included iron-rod, metallic part of Dane gun, multi-faceted spear, piece of stone and a piece of charred wood. Both the right and left sides of the cranium was equally affected with a case involving midline frontal area. Craniectomy around the impaled object was used to remove the objects, two patients had good recovery whilst three succumbed to the injuries, one died from disseminated intravascular coagulopathy and the two were from aspiration pneumonitis complicated by respiratory failure.

Conclusions: Impalement cranio-cerebral injury accounted for about $0.3 \%$ of all cases of traumatic brain injury in our environment. Variable impaled objects were found affecting a different part of the cranium and postoperative outcome depends largely on the preoperative neurological status.
\end{abstract}

Keywords: Impalement injury, Traumatic brain injury, Outcome

\section{Background}

Impalement cranio-cerebral injury is a rare neurosurgical emergency with the potentials for serious morbidity and mortality. Penetrating injuries are the major cause of death in traumatic brain injury, accounting for $40 \%$ of mortality with most resulting from gunshot $[1,2]$. The incidence of impalement cranio-cerebral injury is largely unknown because of its rarity [1].

Penetrating brain injury caused by foreign objects is quite uncommon; this is attributed to the smaller size of the head compared to the rest of the body, in addition to protective reflexes in the face that allow the victim to move away from the injurious object [3-5]. Various

\footnotetext{
* Correspondence: kokoaliyu1@gmail.com

Department of Neurosurgery, Regional Centre for neurosurgery, Usmanu Danfodiyo University Teaching Hospital Sokoto, Sokoto, Nigeria
}

types of impaled objects have been reported, including but not limited to nails, knives, spear, wooden chopstick, brush and screwdrivers [4, 6, 7]. Extraction of impaling objects at the site of injury is strongly discouraged because the outcome is better in a well-designed procedure in a neurosurgical theatre [8-10].

The outcome of cranio-cerebral injury depends on the site of injury, depth of penetration and severity of the damage caused by the impaled object [11, 12]. Early diagnosis, prompt and adequate resuscitation and appropriate neurosurgical intervention is key to favourable outcome.

The incidence of impalement of cranio-cerebral injuries is expected to rise in the West African sub-region because of the menace of sectarian crisis, communal clashes and proliferation of small arms. This call for more research on this field and development of standardise treatment 
Table 1 Biodemographic and clinical characteristics of patients

\begin{tabular}{|c|c|c|c|c|c|}
\hline Variable & $\begin{array}{l}\text { Case } 1 \text { (Figs. 1, 2, 3, } 4 \\
\text { and 5) }\end{array}$ & Case 2 (Figs. 6, 7 and 8) & Case 3 (Fig. 9) & Case 4 (Figs. 10 and 11) & $\begin{array}{l}\text { Case } 5 \text { (Figs. } 12 \\
\text { and 13) }\end{array}$ \\
\hline Age (years) & 18 & 17 & 25 & 70 & 10 \\
\hline Gender & M & M & M & M & M \\
\hline Aetiology & Assault & Accidental discharge & Assault & Road traffic accident & Falls from tree \\
\hline Impaled object & Iron rod & $\begin{array}{l}\text { Metallic part of Dane } \\
\text { gun }\end{array}$ & Multi-faceted spear & Piece of stone & Piece of charred wood \\
\hline $\begin{array}{l}\text { Duration between injury } \\
\text { and presentation (h) }\end{array}$ & 3 & 12 & 1 & 12 & 24 \\
\hline GCS at presentation & 14 & 14 & 4 & 7 & 8 \\
\hline Route & Left frontal & Left frontal & $\begin{array}{l}\text { Right occipito- } \\
\text { cervical }\end{array}$ & Midline frontal & Right frontal \\
\hline Surgical approach & $\begin{array}{l}\text { Left frontal } \\
\text { craniectomy }\end{array}$ & Left frontal craniectomy & Nil & $\begin{array}{l}\text { Midline frontal } \\
\text { craniectomy }\end{array}$ & $\begin{array}{l}\text { Right frontal } \\
\text { craniectomy }\end{array}$ \\
\hline $\begin{array}{l}\text { Glasgow outcome score } \\
\text { (GOS) }\end{array}$ & Good recovery (GOS. 5) & Good recovery (GOS. 5) & Death (GOS. 1) & Death (GOS. 1) & Death (GOS. 1) \\
\hline
\end{tabular}

algorithm that would facilitate management and improve neurosurgical outcome.

The objectives of this paper were to report the clinical presentation and management outcome of patients admitted with impalement cranio-cerebral injuries in our centre.

\section{Case presentation}

This is a retrospective analysis of all cases of impalement brain injury managed from January 2015 to November

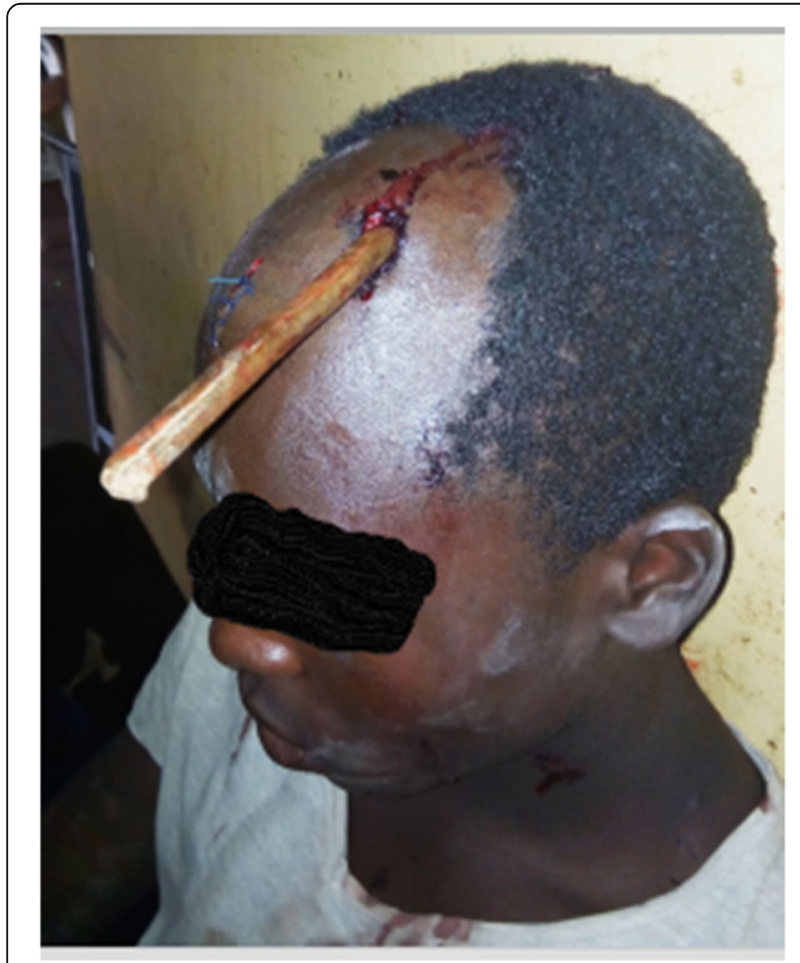

Fig. 1 Implaed iron rod at presentation
2018. Biodemographic characteristics, clinical details, neuroimaging findings and outcomes measured using Glasgow outcome score were noted. Clinical photographs of the cases were also retrieved. Results were presented in figures and tables. Out of the total 1913 cases of traumatic brain injury managed over the study period, 5 cases $(0.26 \%)$ had impalement injury. Clinical details and outcomes of the cases were shown in (Table 1).

The third patient (case 3) (Fig. 9) was a political thug that was assaulted by his own cousin-brother with a multi-faceted spear, developed disseminated intravascular coagulopathy with bleeding from all body orifices and succumbed before he could have surgical intervention. Whilst cases 4 and 5 presented with seizure and aspiration pneumonitis in addition to severe traumatic

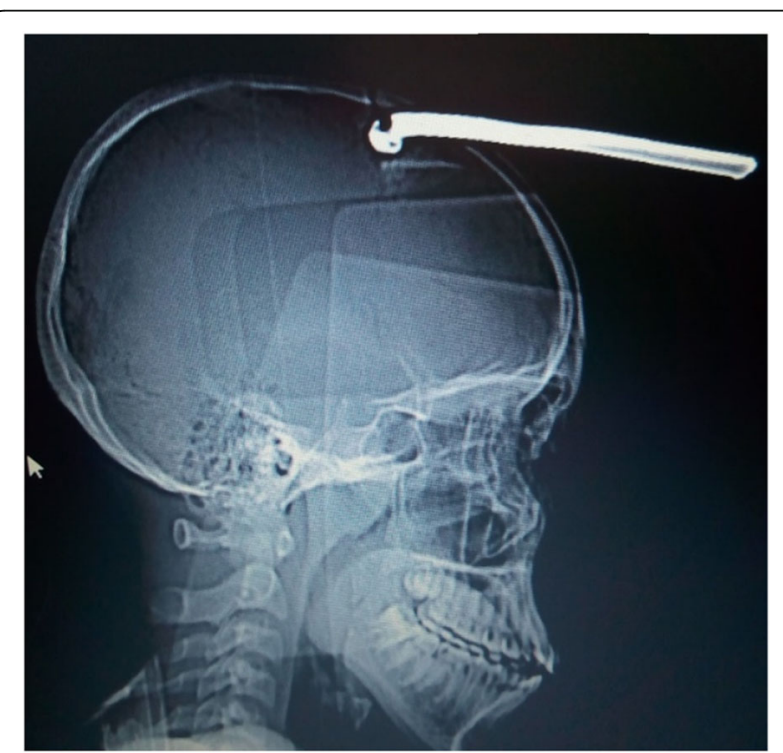

Fig. 2 Skull xray showing implaed iron rod 


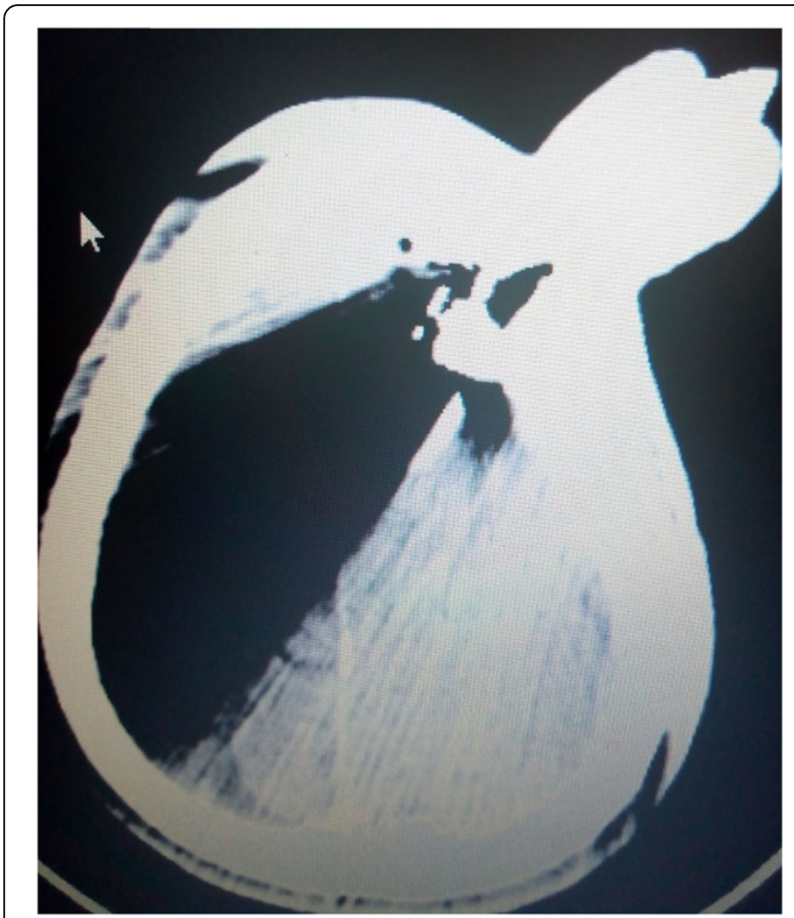

Fig. 3 CT scan showing an impled metal

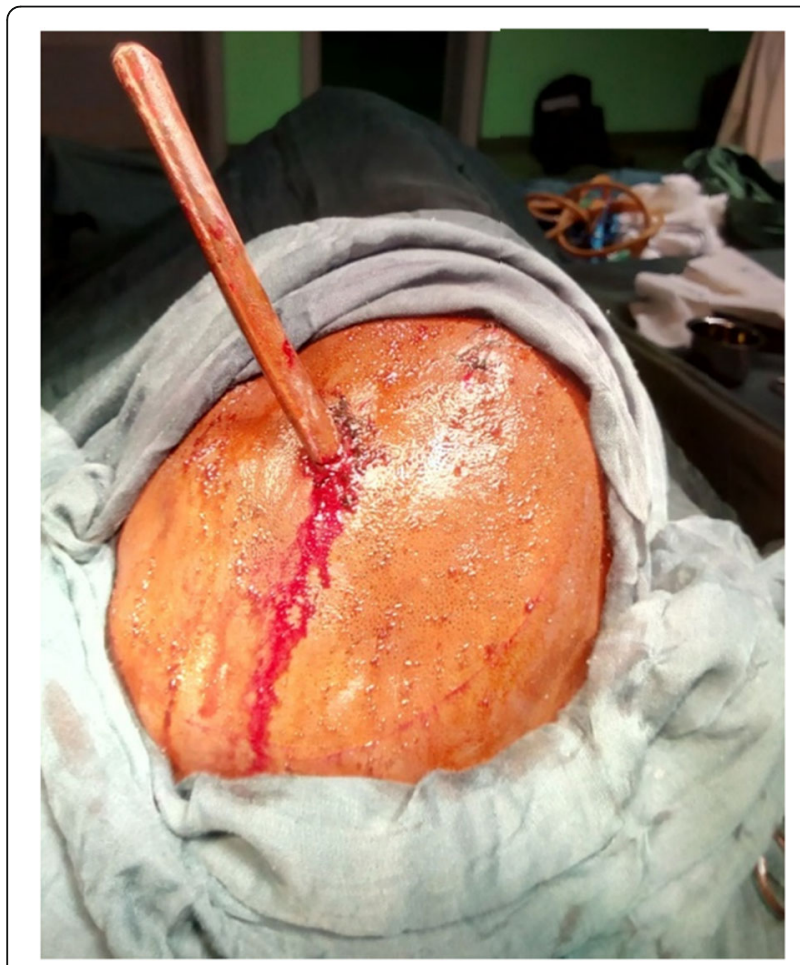

Fig. 4 Implaed iron rod

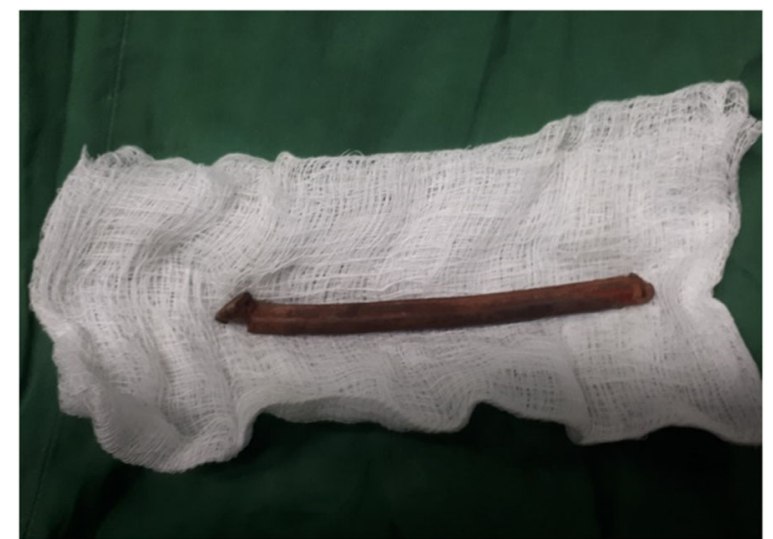

Fig. 5 Iron rod after removal

brain injury, they died on days 6 and 8 post-surgery respectively from respiratory failure. All the patients had intravenous antibiotics and anticonvulsant medications. Most of the patients (4/5) had their impaled object removed by craniectomy around the object except the fourth case that was under local anaesthesia because of a very low Glasgow scale score (7/15) in an elderly patient presenting with features of aspiration pneumonitis.

From our report, it is obvious that impalement craniocerebral injury accounted for about $0.3 \%$ of all cases of traumatic brain injury. Majority of our patients were younger than 45 years $(4 / 5)$ and all were males. These findings are in keeping with the report of the incidence of traumatic brain injury being commoner in males below the age of 45 years worldwide [13]. We observed different types of objects resulting in impalement injury (Figs. 1, 2, 3, 4, 5, 6, 7, 8, 9, 10, 11, 12 and 13). This is in tandem with the findings of previous earlier studies [4, $7,14]$. The aetiological factors identified in this report included assault, accidental Dane gun discharge, road

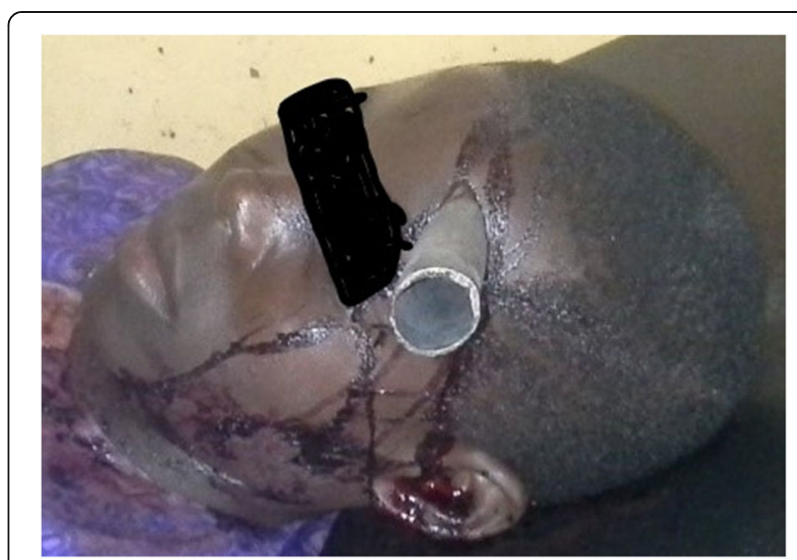

Fig. 6 Implaed metallic part of a dane gun 


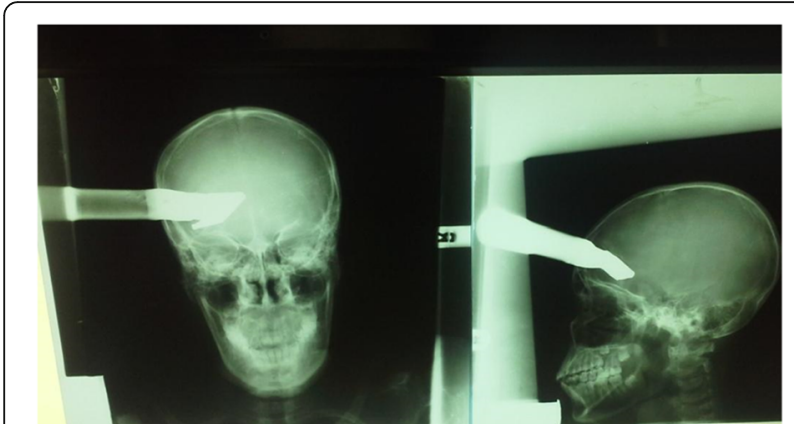

Fig. 7 Xrays showing imapled metallic part of dane gun

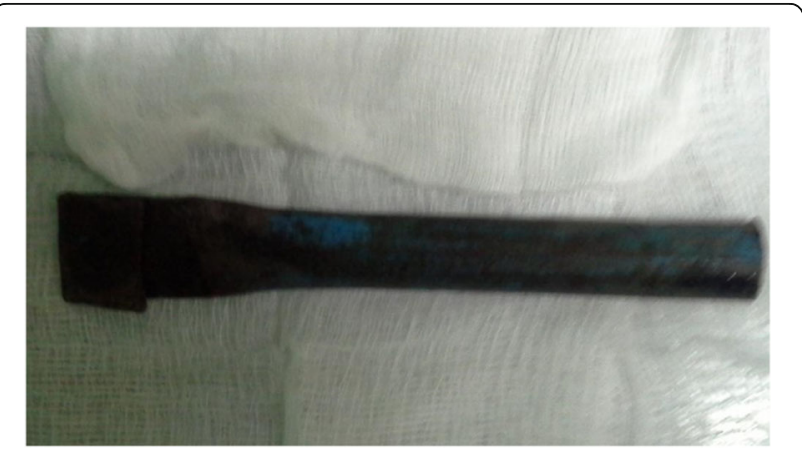

Fig. 8 Metallic part of a dane gun after removal

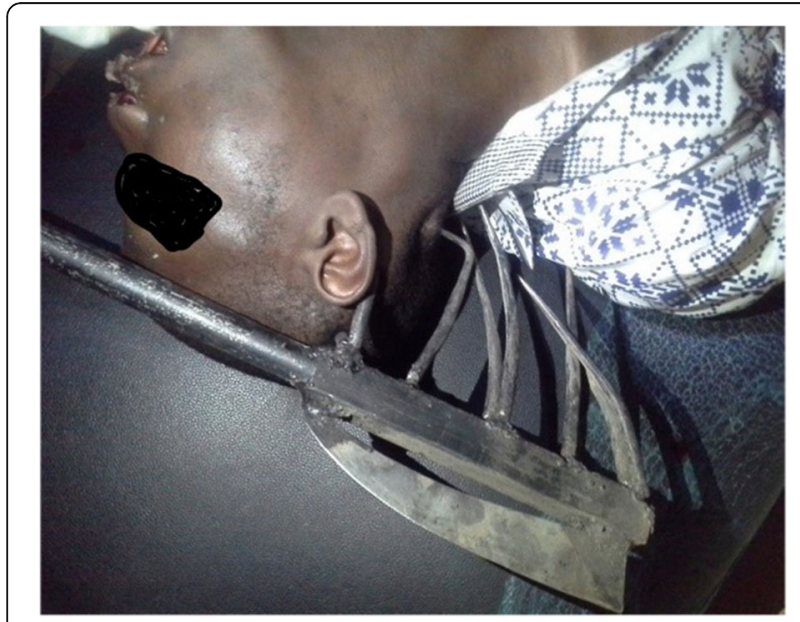

Fig. 9 Impaled multifaceted spear in cranio-cervical area

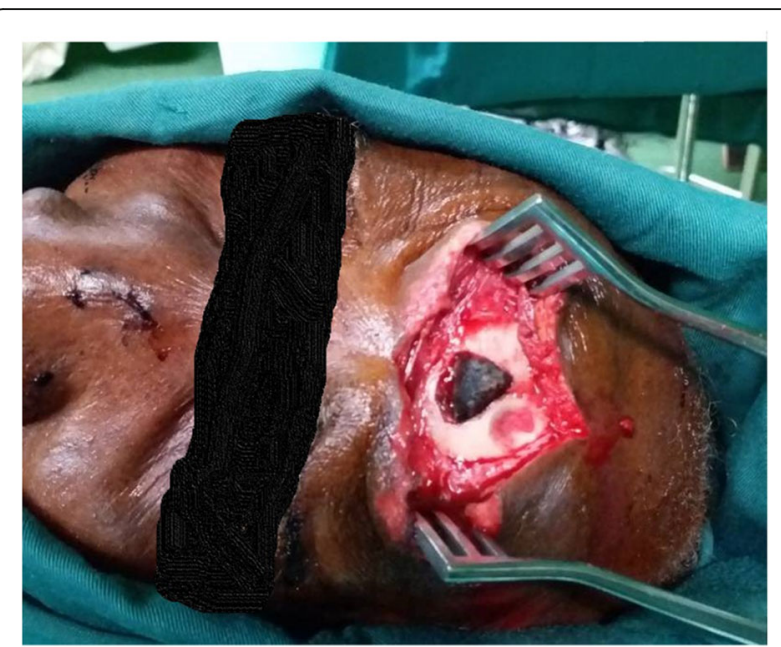

Fig. 10 Impaled midline frontal piece of stone

traffic accidents and fall from a tree. Other authors have also reported similar findings [15]. Both the left and right sides of the cranium were equally affected in our study with one case involving the midline frontal region (Figs. 1, 2, 3, 4, 5, 6, 7, 8, 9, 10, 11, 12 and 13). Our findings slightly differ from a previous earlier study [3].

Three of our patients presented with severe traumatic brain injury with Glasgow coma scale score of 8 and below whilst the remaining two had mild traumatic brain injury with Glasgow coma scale score of 14. This is in contrast to a series of Yusuf et al. who found

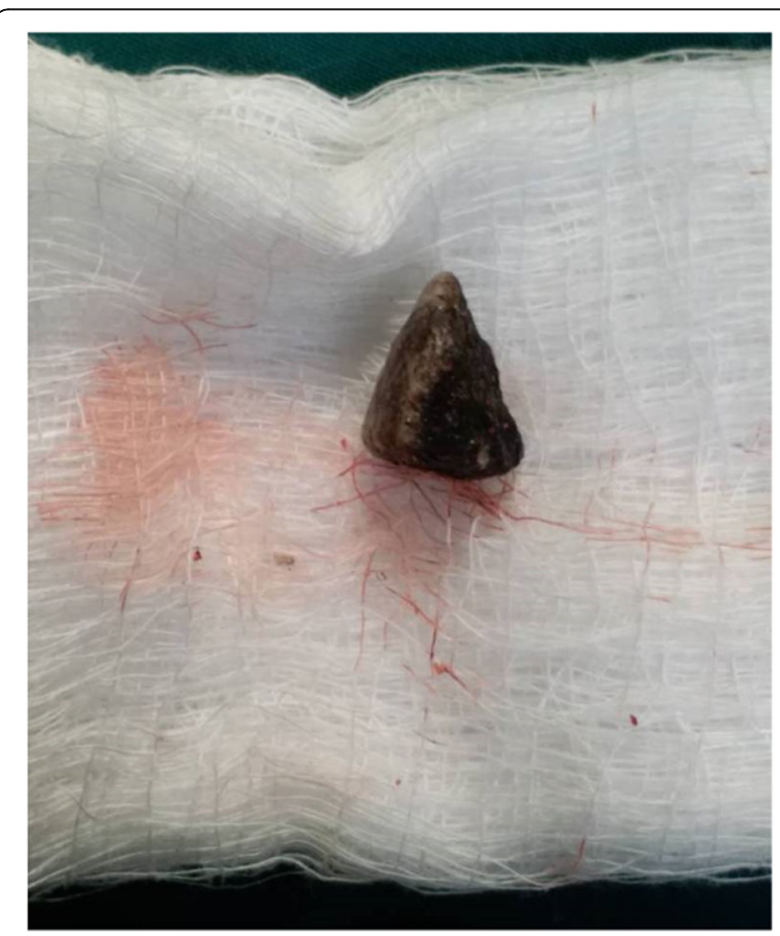

Fig. 11 Piece of stone after removal 


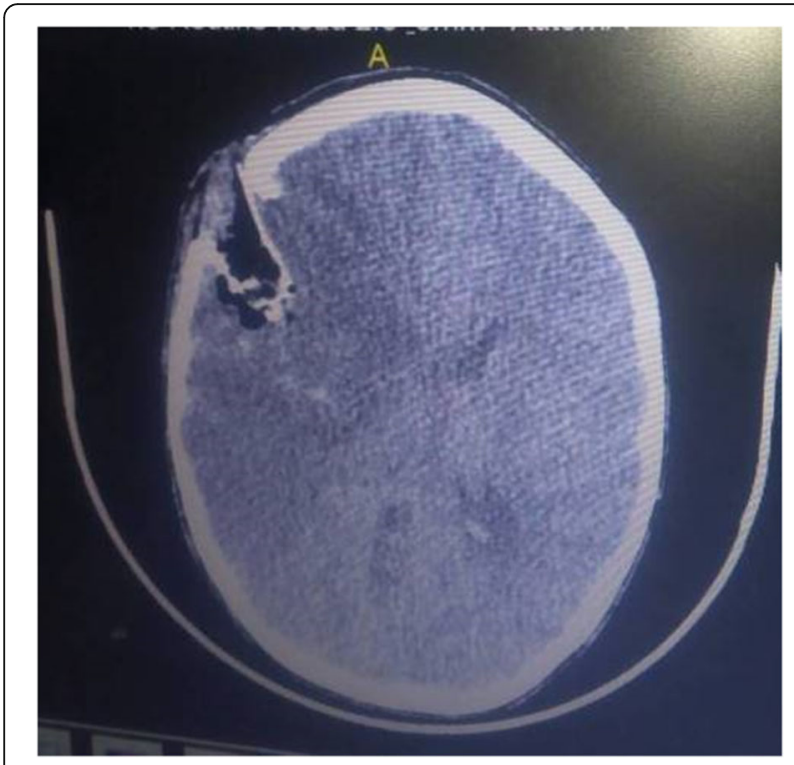

Fig. 12 Axial slice CT scan showing right frontal imapled charred wood appearing as hypodense lesion

majority of their patients presenting with Glasgow coma scale score of 15 [3]. Impaled objects were removed by craniectomy around the object for all patients except the third case that died from disseminated intravascular coagulopathy before surgical intervention. This agreed with the previous study but contrary to the report of other authors that reported craniotomy around the impaled object, against craniectomy performed in our series [3, 12]. Unlike our findings, most of the previous earlier series by other authors had a good outcome. The poor

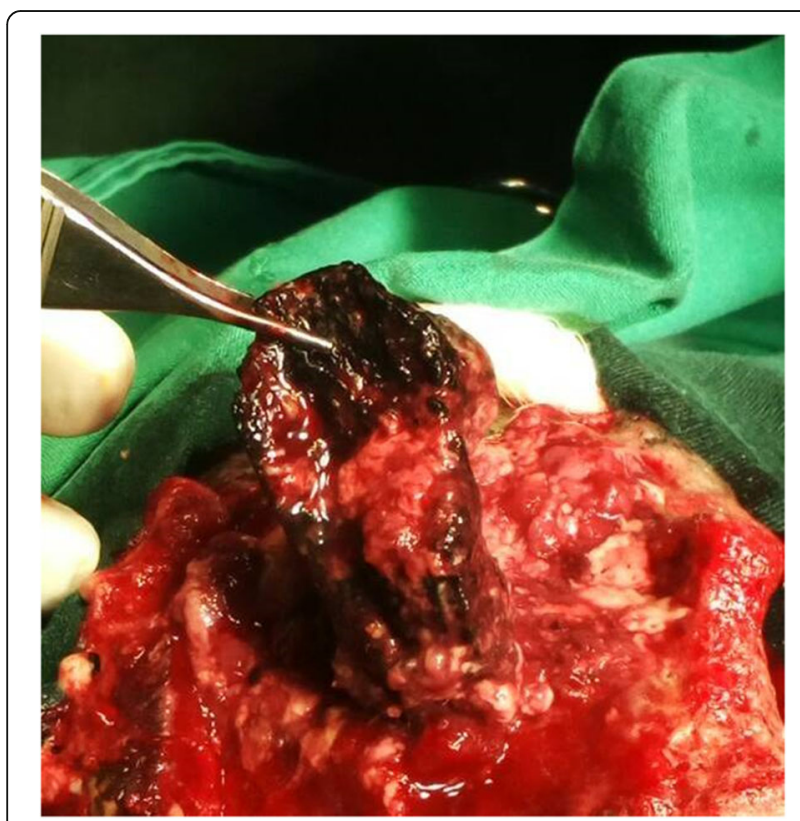

Fig. 13 Intraoperative image showing impaled charred wood outcome observed in our series (three cases of mortalities) was attributed to the severity of brain injury, as all the mortalities presented with Glasgow coma scale score of eight and below. However, the overall outcome of impalement injury depends on the site of injury and the extent of damage caused by the objects [11].

\section{Conclusions}

We managed a rare form of severe impalement brain injuries. We also found that patients with pre-operative higher Glasgow coma scale score have favourable outcome compared to low GCS; therefore, prompt resuscitation, antibiotics and anticonvulsant therapies and timely surgical intervention are recommended for a better outcome.

\section{Acknowledgements}

We thank all staff of the Department of neurosurgery for their commitment in managing our patients.

\section{Authors' contributions}

$\mathrm{AM}$ and $\mathrm{AL}$ contributed to the conception of the research, preparation of clinical details and literature review. The authors read and approved the final manuscript.

\section{Funding}

None.

\section{Availability of data and materials}

The data can be found from case files of the patients at the medical record section of the department of neurosurgery and surgical images archive of the Department of Neurosurgery, Usmanu Danfodiyo University Teaching Hospital Sokoto, Nigeria.

\section{Ethics approval and consent to participate} Not applicable

\section{Consent for publication}

Consent to publish has been obtained from the patients/relations of the patients involved.

\section{Competing interests}

The authors declare that they have no competing interests.

Received: 26 July 2019 Accepted: 14 February 2020

Published online: 03 March 2020

\section{References}

1. Quang CY, Rosal LM, Blair SG, Simmons JD, Rusyniak WG, Brevard SB. Craniofacial impalement injury: projectile fragment to the head. Arch Trauma Res. 2018;7:30-2.

2. Adekoya N, Thurman DJ, White DD, Webb KW. Surveillance for traumatic Brain Injury Deaths-United States, 1989-1998. Washington, DC: Centers for Disease Control and Prevention NCfIPaC, MMWR Surveillance Summaries; 2002. p. 1-16.

3. Yusuf AS, Mahmud MR, Alfin JD, Adeleke NA. Clinical presentation and outcome of impalement cranio cerebral injuries - a case series. JWACS. 2017;7(2):112-23.

4. Jimoh AO, Guga DA, Mathew M, Danjuma S. Cranial Impalement of a Falling Fence Spike in a Child: A Case Report. J Surg. 2016;4(2):31-4. https:// doi.org/10.11648/j.js.20160402.16.

5. Akhiwu BI, Adoga AS, Binitie OP, Ani CC, Iweagwu M, Adetutu O, et al. Impalement head injury with a spear. JWACS. 2016;6(2):113-24.

6. Shuaib KA, Muhammed MM, Ikechukwu Cl. Oro-cranial penetrating pencil injury. Ann Saudi Med. 2012;32(5):534-6. https://doi.org/10.5144/0256-4947. 2012.30.4.1100. 
7. Damn A, Lauritssen A, Klemp K, Rikke VN. Transorbital impalement by a wooden stick in a 3-year-old child. BMJ Case Rep. 2015. https://doi.org/10. 1136/bcr-2015211885.

8. Binitie OP. Impalement head injuries. JWACS. 2017;2:X-Xii.

9. Binitie OP, Shilong DJ, Ugwu BT, Ekedigwe JE, Oyeniran OO, Adighije PF, et al. Impalement head injury with serrated meat knife. JWACS. 2012;2:67-74.

10. Chika TA, Mathew EO. Management of a nail impalement injury to the brain in a non-neurosurgical Centre: a case report and review of the literature. Int J Surg Case Rep. 2016;19:115-8.

11. Abdulbaki A, Al-Otaibi F, Almalki A, Alohaly N, Baeesa S. Transorbital craniocerebral occult penetrating injury with cerebral abscess complication. Case Rep Ophthalmol Med. 2012;2012:742186. https://doi.org/10.1155/2012/ 742186

12. Wataru T, Kaho Y, Akira E, Yasuhiro O. A Case of Impalement Brain Injury That Could Achieve Good Neurological Outcome by Introducing Early Sedation and Immobilization Strategy. Case Rep Ophthalmol Med. 2018; 3025717:4. https://doi.org/10.1155/2018/3025717.

13. John B, Allen WH. The epidemiology of traumatic brain injury: a review. Epilepsia. 2003;44(10):2-10.

14. Kazim SF, Shamim MS, Tahir MZ, Enam SA, Waheed S. Management of penetrating brain injury. J Emerg Trauma Shock. 2011;4(3):395-402.

15. Andrew JG, Taylor JA, Janel S, Nader D, Severson MA III, et al. Impalement brain injury from steel rod causing injury to jugular bulb: case report and review of the literature. Brain Inj. 2014;28(12):1617-21. https://doi.org/10. 3109/02699052.2014.934284.

\section{Publisher's Note}

Springer Nature remains neutral with regard to jurisdictional claims in published maps and institutional affiliations.

\section{Submit your manuscript to a SpringerOpen ${ }^{\circ}$ journal and benefit from:}

- Convenient online submission

- Rigorous peer review

- Open access: articles freely available online

- High visibility within the field

- Retaining the copyright to your article

Submit your next manuscript at $\boldsymbol{\nabla}$ springeropen.com 